\title{
Avaliação físico-química e sensorial de frutos de genótipos melhorados de mamoeiro ${ }^{1}$
}

\author{
Eliseth de Souza Viana², Ronielli Cardoso Reis ${ }^{2}$, \\ Siomara Costa Santana da Silva ${ }^{3}$, Taís Teixeira das Neves ${ }^{4}$, Jaciene Lopes de Jesus ${ }^{2}$
}

\begin{abstract}
Physical-chemical and sensorial evaluation of improved genotypes of papaya fruits

The sustainability and expansion of the papaya crop depends on the development of genotypes with superior quality to satisfy the demands of farmers. This study aimed at evaluating the physicalchemical and sensorial characteristics of papaya fruits in order to identify new genotypes with potential for the market. Fruits from improved genotypes of the Solo (L60, L47-05, L47-08 and H54.78) and Formosa (L33 and H36.45) groups, as well as the commercial varieties Tainung $n^{\circ} 1$ and Sunrise Solo were evaluated. Analyses of pulp yield, weight, length, diameter (fruit and internal cavity), pulp firmness and color, besides sensorial evaluation, were performed. The L47-05 and L47-08 breeding lines from the Solo group had the highest values for fruit weight $(838.30 \mathrm{~g}$ and $803.94 \mathrm{~g}$, respectively) and firmness ( $8.35 \mathrm{kgf} \mathrm{cm}^{-2}$ and $7.74 \mathrm{kgf} \mathrm{cm}^{-2}$, respectively), showing to be more resistant to mechanical damage. The Tainung $\mathrm{n}^{\circ} 1$ cultivar presented the highest values for weight (842.77 g), length $(20.76 \mathrm{~cm})$ and diameter $(9.70 \mathrm{~cm})$. Genotypes from the Solo group (L47-05, L47-08 and H54.78) and the Sunrise Solo control showed soluble solids content above $14{ }^{\circ}$ Brix. The sensory acceptance of the H54.78 hybrid was statistically equal to the Sunrise Solo control for all assessed sensory attributes. The H36.45 and L33 genotypes (Formosa group) were also statistically equal to the Tainung $\mathrm{n}^{\mathrm{o}} 1$ control for all assessed sensory attributes. Based on fruit quality, the H54.78 (Solo group) and the H36-45 and L33 (Formosa group) genotypes are the most promising for the market and can compete with the Sunrise Solo and Tainung $\mathrm{n}^{\mathrm{o}} 1$ commercial cultivars.
\end{abstract}

KEY-WORDS: Carica papaya L.; physical-chemical characterization; genetic breeding.

\section{INTRODUÇÃO}

O mamoeiro (Carica Papaya L.) é uma das fruteiras mais cultivadas e consumidas nas regiões tropicais e subtropicais do mundo. Com produção anual mundial de aproximadamente 12,4 milhões

\section{RESUMO}

A sustentabilidade e a expansão da cultura do mamoeiro dependem do desenvolvimento de genótipos com características superiores, para atender às demandas dos agricultores. Este estudo objetivou avaliar frutos de mamoeiro, quanto às características físico-químicas e sensoriais, visando a identificar novos genótipos com potencial para o mercado. Foram avaliados frutos de genótipos melhorados do grupo Solo (L60, L47-05, L47-08 e H54.78) e do grupo Formosa (L33 e H36.45) e as variedades comerciais Tainung $\mathrm{n}^{\mathrm{o}} 1$ e Sunrise Solo. Analisouse o rendimento de polpa, peso, comprimento, diâmetro (fruto e cavidade interna) e firmeza e cor da polpa, além das avaliações sensoriais. As linhagens L47-05 e L47-08, do grupo Solo, apresentaram os maiores valores para peso $(838,30 \mathrm{~g}$ e $803,94 \mathrm{~g}$, respectivamente) e firmeza de fruto $\left(8,35 \mathrm{kgf} \mathrm{cm}^{-2} \mathrm{e}\right.$ $7,74 \mathrm{kgf} \mathrm{cm}^{-2}$, respectivamente), portanto, são mais resistentes a injúrias mecânicas. A cultivar Tainung $\mathrm{n}^{\mathrm{o}} 1$ apresentou os maiores valores para peso $(842,77 \mathrm{~g})$, comprimento $(20,76 \mathrm{~cm})$ e diâmetro $(9,70 \mathrm{~cm})$. Os genótipos do grupo Solo L47-05, L47-08, H54.78 e a testemunha Sunrise Solo apresentaram teor de sólidos solúveis acima de $14{ }^{\circ}$ Brix. A aceitação do híbrido H54.78 foi estatisticamente igual à da testemunha Sunrise Solo para todos os atributos sensoriais avaliados. Os genótipos H36.45 e L33, do grupo Formosa, foram estatisticamente iguais à testemunha Tainung $\mathrm{n}^{\circ} 1$ para todos os atributos. Com base na qualidade dos frutos, os genótipos H54.78 (grupo Solo) e H36.45 e L33 (grupo Formosa) são os mais promissores para o mercado e podem competir com as cultivares comerciais Sunrise Solo e Tainung $\mathrm{n}^{\mathrm{o}} 1$.

PALAVRAS-CHAVE: Carica papaya L.; caracterização físicoquímica; melhoramento genético.

de toneladas, seus principais produtores são a Índia, Brasil, República Dominicana e Nigéria (FAO 2013). Trata-se de uma cultura de importância expressiva para o Brasil, cuja produção foi de 1,51 milhões de toneladas, em 2012, correspondendo a $12 \%$ do mercado mundial. O Estado da Bahia destaca-se como o maior

1. Trabalho recebido em abr./2015 e aceito para publicação em ago./2015 (http://dx.doi.org/10.1590/1983-40632015v4535008).

2. Empresa Brasileira de Pesquisa Agropecuária (Embrapa Mandioca e Fruticultura), Cruz das Almas, BA, Brasil.

E-mails: eliseth.viana@embrapa.br, ronielli.reis@embrapa.br, jaciene.lopes@embrapa.br.

3. Universidade Estadual de Feira de Santana (UEFS), Feira de Santana, BA, Brasil.E-mail: sio.ois1@gmail.com.

4. Universidade Federal do Recôncavo da Bahia (UFRB), Cruz das Almas, BA, Brasil._E-mail: tai_neves@yahoo.com.br. 
produtor nacional, seguido pelo Espírito Santo, Ceará e Rio Grande do Norte, que, juntos, são responsáveis por cerca de $87 \%$ da produção nacional (IBGE 2013).

Os frutos do mamoeiro apresentam sabor e aroma agradáveis e sua polpa possui características sensoriais e nutricionais que o tornam um alimento saudável para pessoas de todas as idades. A sua composição química varia de acordo com a cultivar, clima, tratos culturais, local, época em que é produzido e estádio de maturação (Souza et al. 2009).

A polpa do mamão destaca-se pelo baixo valor energético e baixa concentração de carboidratos, bem como pelo elevado valor nutritivo, devido à presença de sais minerais e vitamina C. As variedades Formosa e Sunrise Solo apresentam, em $100 \mathrm{~g}$ de polpa, respectivamente, $45 \mathrm{kcal}$ e $40 \mathrm{kcal} ; 11,06 \%$ e 10,4\% de carboidratos; $25 \mathrm{mg}$ e $22 \mathrm{mg}$ de cálcio; $17 \mathrm{mg}$ e $22 \mathrm{mg}$ de magnésio; $222 \mathrm{mg}$ e $126 \mathrm{mg}$ de potássio; e 78,5 mg e 82,2 mg de vitamina C (Taco 2011).

Entretanto, os produtores dispõem de poucas cultivares de mamoeiro para plantio, o que tem sido um dos principais fatores limitantes à obtenção de altas produtividades, associadas às características de frutos que possam atender novos mercados. Assim, a sustentabilidade e expansão da cultura dependem do desenvolvimento de genótipos com características superiores, resistentes a pragas e doenças, e tolerantes à seca, para atenderem à constante demanda dos agricultores (Oliveira et al. 2010, Dias et al. 2011).

É importante considerar que não basta realizar avaliações de novas variedades sob o aspecto agronômico, uma vez que os consumidores estão habituados às características relacionadas ao perfil sensorial dos frutos pertencentes aos grupos Solo e Formosa. Assim, a realização de pesquisas na área de Ciência e Tecnologia de Alimentos, que complementem e apoiem o programa de melhoramento genético de mamoeiro, revestem-se de grande importância.

Este estudo objetivou avaliar frutos de linhagens e híbridos de mamoeiro, quanto às características físico-químicas e sensoriais, visando a identificar novos genótipos com potencial para lançamento no mercado.

\section{MATERIAL E MÉTODOS}

O experimento foi instalado em Cruz das Almas (BA) (1240'39''S, 3906'22''W e 226 m de altitude), em área experimental da Embrapa Mandioca e Fruticultura. Para avaliar os frutos de oito genótipos de mamoeiro, utilizou-se o delineamento de blocos casualizados com quatro repetições, contendo seis plantas por parcela, totalizando 192 plantas. O plantio foi realizado no espaçamento de 3,0 m entre as linhas e 1,8 m entre as plantas, utilizando-se irrigação localizada com microaspersores e seguindo-se todos os tratos culturais recomendados para a cultura (Martins \& Costa 2003).

Foram avaliados frutos de quatro genótipos melhorados do grupo Solo (L60, L47-05, L47-08 e H54.78), dois do grupo Formosa (L33 e H36.45) e as variedades comerciais Tainung $\mathrm{n}^{\mathrm{o}} 1$ e Sunrise Solo. Os frutos foram colhidos no estádio 2 de maturação (casca até $25 \%$ amarela) e avaliados no estádio 5 de maturação (casca completamente amarela).

As avaliações dos genótipos, quanto às características físicas e físico-químicas, foram efetuadas de setembro de 2012 a julho de 2013 e as avaliações sensoriais realizadas em maio de 2013. As análises laboratoriais foram efetuadas seguindo-se o mesmo delineamento experimental do campo.

Para a realização das análises físicas, foram avaliados, individualmente, de três a cinco frutos de cada genótipo por bloco. As análises físicas compreenderam o rendimento de polpa (RP, expresso em $\%$ ), firmeza do fruto com casca ( $\mathrm{FF}$, em $\mathrm{kgf} \mathrm{cm}^{-2}$ ), diâmetro do fruto (DF, em $\mathrm{cm}$ ), diâmetro da cavidade interna dos frutos (DCI, em cm) e cor da polpa. O rendimento foi determinado em balança semianalítica, a firmeza por meio de penetrômetro analógico com ponteira de $8 \mathrm{~mm}$ de diâmetro e os diâmetros do fruto e da cavidade interna com o auxílio de paquímetro. A cor da polpa foi avaliada por meio de colorímetro (Konica Minolta, modelo CR400, sistema CIELAB, iluminante D65). Foram avaliados os atributos cromáticos L* (luminosidade), C* (croma/saturação) e $\mathrm{h}^{*}$ (tonalidade/ângulo de cor).

Para as análises físico-químicas, de três a cinco frutos de cada bloco foram despolpados, formando uma amostra homogênea, a qual foi avaliada em triplicata. Foram realizadas análises de acidez titulável (AT, em \% de ácido cítrico), sólidos solúveis (SS, em ${ }^{\circ}$ Brix), pH e relação SS/AT, segundo o IAL (2008).

Os testes de aceitação sensorial e intenção de compra foram realizados em duas etapas, por 52 julgadores não treinados, seguindo-se o delineamento em blocos casualizados. Primeiramente, os frutos foram cortados ao meio (longitudinalmente), recobertos com filme plástico de cloreto de polivinila (PVC) e expostos sobre uma mesa, para avaliação da aparência interna e intenção de compra. Na segunda etapa, os 
frutos foram cortados em cubos de $3 \mathrm{~cm}$ e apresentados de forma monádica e em cabines individuais, para avaliação da aceitação dos atributos cor, aroma, sabor, textura, aceitação global e intenção de compra.

Para o teste de aceitação sensorial, utilizou-se escala hedônica de nove pontos, sendo os extremos "desgostei muitíssimo" e "gostei muitíssimo", e, para a intenção de compra, escala de cinco pontos, sendo os extremos "eu certamente compraria" (5) e "eu certamente não compraria" (1). Nessa etapa, realizou-se, também, o diagnóstico dos atributos, utilizando-se escala de intensidade de nove pontos, para os atributos cor (muito clara/muito escura), aroma (fraco/forte), sabor (fraco/forte) e textura na boca (muito mole/muito dura), como descrito em Meilgaard et al. (2006).

Os dados das características físicas e físico-químicas e da aceitação sensorial dos frutos foram submetidos à análise de variância e as médias comparadas pelo teste Tukey, a $5 \%$, com o auxílio do programa Sisvar (Ferreira 2010). As porcentagens de aprovação dos atributos sensoriais foram calculadas com base na soma das notas iguais ou superiores a 6. Os dados de intenção de compra foram apresentados em porcentagem.

\section{RESULTADOS E DISCUSSÃO}

Os frutos dos genótipos do grupo Solo não diferiram quanto ao rendimento de polpa (RP), com valor médio de $53 \%$, entretanto, apresentaram diferença significativa $(\mathrm{p}<0,05)$ nas medidas de peso $(\mathrm{PF})$, comprimento $(\mathrm{CF})$ e diâmetro de fruto (DF) (Tabela 1). As linhagens L47-05 e L47-08 apresentaram os maiores PF $(838,30 \mathrm{~g}$ e $803,94 \mathrm{~g}) \mathrm{e}$ a testemunha Sunrise Solo o menor CF $(13,91 \mathrm{~cm})$. $\mathrm{O}$ diâmetro médio dos frutos dos genótipos do grupo Solo foi de $9,16 \mathrm{~cm}$, sendo que as linhagens L47-05 e L47-08 apresentaram valores de 9,80 cm e 9,72 cm, respectivamente, e diferiram significativamente do genótipo H54.78, que apresentou 8,50 cm de diâmetro.

Apesar das diferenças entre os diâmetros dos frutos, não foi observada diferença significativa $(p>0,05)$ em relação ao diâmetro da cavidade interna, com valor médio de $4,37 \mathrm{~cm}$ (Tabela 1). Frutos com dimensões iguais às da testemunha Sunrise Solo podem atender os consumidores dessa variedade, enquanto aqueles com dimensões maiores podem atender famílias maiores ou agroindústrias de processamento, desde que apresentem características sensoriais desejáveis. Segundo Dias et al. (2011), o diâmetro da cavidade interna está relacionado com a qualidade dos frutos, sendo que frutos com menor diâmetro dessa cavidade, geralmente, apresentam maior quantidade de polpa.

As linhagens L47-05 e L47-08 do grupo Solo apresentaram os maiores valores de firmeza de fruto (FF) $\left(8,35 \mathrm{kgf} \mathrm{cm}^{-2}\right.$ e 7,74 $\mathrm{kgf} \mathrm{cm}^{-2}$, respectivamente) e diferiram estatisticamente dos demais genótipos, o que demonstra que os frutos dessas linhagens apresentam casca e/ou polpa mais firmes (Tabela 1).

A firmeza é de fundamental importância para o transporte dos frutos, já que influencia diretamente na resistência dos mesmos contra choques mecânicos,

Tabela 1. Médias das características físicas e físico-químicas de híbridos e linhagens de mamoeiro dos grupos Solo e Formosa (Cruz das Almas, BA, 2015).

\begin{tabular}{|c|c|c|c|c|c|c|c|c|c|c|c|c|c|}
\hline & \multicolumn{13}{|c|}{ Grupo Solo } \\
\hline Genótipo & $\mathrm{RP}$ & $\mathrm{PF}$ & $\mathrm{CF}$ & DF & DCI & $\mathrm{FF}$ & $\mathrm{L}^{*}$ & $\mathrm{C}^{*}$ & $\mathrm{~h}^{*}$ & AT & $\mathrm{SS}$ & $\mathrm{pH}$ & SS/AT \\
\hline L47-05 & $53,71 \mathrm{a}$ & $838,30 \mathrm{a}$ & $18,54 \mathrm{a}$ & $9,80 \mathrm{a}$ & $4,42 \mathrm{a}$ & $8,35 \mathrm{a}$ & $64,57 \mathrm{a}$ & $61,69 \mathrm{a}$ & $67,06 \mathrm{a}$ & $0,09 \mathrm{ab}$ & $14,92 \mathrm{a}$ & $5,09 \mathrm{a}$ & $161,24 \mathrm{a}$ \\
\hline L47-08 & 49,87 a & 803,94 a & $18,08 \mathrm{a}$ & $9,72 \mathrm{a}$ & $5,00 \mathrm{a}$ & $7,74 \mathrm{a}$ & $57,42 \mathrm{ab}$ & $53,33 \mathrm{~b}$ & $53,70 \mathrm{~b}$ & $0,11 \mathrm{a}$ & $15,02 \mathrm{a}$ & $5,35 \mathrm{a}$ & $139,74 \mathrm{a}$ \\
\hline L60 & $52,32 \mathrm{a}$ & $366,02 \mathrm{~b}$ & $14,17 \mathrm{a}$ & $8,98 \mathrm{ab}$ & $3,49 \mathrm{a}$ & $1,87 \mathrm{~b}$ & $61,28 \mathrm{ab}$ & $43,71 \mathrm{c}$ & $58,52 \mathrm{ab}$ & $0,08 \mathrm{~b}$ & $11,15 \mathrm{~b}$ & $5,31 \mathrm{a}$ & $143,90 \mathrm{a}$ \\
\hline H54.78 & $56,79 \mathrm{a}$ & $511,67 \mathrm{~b}$ & $14,12 \mathrm{a}$ & $8,50 \mathrm{~b}$ & $5,10 \mathrm{a}$ & $3,46 b$ & $52,48 \mathrm{~b}$ & $51,62 \mathrm{bc}$ & $54,05 \mathrm{ab}$ & $0,09 \mathrm{ab}$ & $15,10 \mathrm{a}$ & $5,39 \mathrm{a}$ & $172,57 \mathrm{a}$ \\
\hline Sunrise Solo & $52,55 \mathrm{a}$ & $471,54 \mathrm{~b}$ & $13,91 \mathrm{~b}$ & $8,83 \mathrm{ab}$ & $3,82 \mathrm{a}$ & $1,55 \mathrm{~b}$ & $57,70 \mathrm{ab}$ & $50,53 \mathrm{bc}$ & $57,63 \mathrm{ab}$ & $0,09 \mathrm{ab}$ & $14,17 \mathrm{a}$ & $5,11 \mathrm{a}$ & $166,70 \mathrm{a}$ \\
\hline Média & $53,05^{\mathrm{ns}}$ & $598,30^{*}$ & $15,76^{*}$ & $9,16^{*}$ & $4,37^{\mathrm{ns}}$ & $4,59^{*}$ & $58,69^{*}$ & $52,18^{*}$ & $58,19^{*}$ & $0,09 *$ & $14,07 *$ & $5,25^{\mathrm{ns}}$ & $158,01^{\text {ns }}$ \\
\hline \multirow[t]{2}{*}{ CV (\%) } & 6,59 & 20,16 & 22,87 & 5,47 & 22,21 & 28,03 & 7,24 & 6,90 & 8,87 & 11,29 & 6,79 & 5,89 & 13,44 \\
\hline & \multicolumn{13}{|c|}{ Grupo Formosa } \\
\hline Genótipo & $\mathrm{RP}$ & PF & $\mathrm{CF}$ & DF & DCI & FF & $\mathrm{L}^{*}$ & $\mathrm{C}^{*}$ & $\mathrm{~h}^{*}$ & AT & SS & $\mathrm{pH}$ & SS/AT \\
\hline L33 & $57,76 \mathrm{a}$ & $672,94 \mathrm{~b}$ & $19,38 \mathrm{~b}$ & $9,49 \mathrm{~b}$ & $6,13 \mathrm{a}$ & $2,04 \mathrm{a}$ & $56,24 \mathrm{~b}$ & $48,73 \mathrm{~b}$ & $57,27 \mathrm{~b}$ & $0,09 \mathrm{a}$ & $13,09 \mathrm{a}$ & $5,24 \mathrm{a}$ & $146,27 \mathrm{a}$ \\
\hline H36.45 & $60,80 \mathrm{a}$ & $709,11 \mathrm{~b}$ & $17,18 \mathrm{~b}$ & $8,64 \mathrm{~b}$ & $4,47 \mathrm{a}$ & $3,65 \mathrm{a}$ & $66,35 \mathrm{a}$ & $58,92 \mathrm{a}$ & $72,53 \mathrm{a}$ & $0,08 \mathrm{a}$ & $13,46 \mathrm{a}$ & $5,16 \mathrm{a}$ & $165,28 \mathrm{a}$ \\
\hline Tainung $\mathrm{n}^{\circ} 1$ & $54,77 \mathrm{a}$ & $1.146,27 \mathrm{a}$ & $25,73 \mathrm{a}$ & $10,97 \mathrm{a}$ & $4,55 \mathrm{a}$ & $2,12 \mathrm{a}$ & $60,14 \mathrm{ab}$ & $47,32 \mathrm{~b}$ & $56,30 \mathrm{~b}$ & $0,07 \mathrm{a}$ & $11,80 \mathrm{a}$ & $5,21 \mathrm{a}$ & $163,63 \mathrm{a}$ \\
\hline Média & $57,77^{\mathrm{ns}}$ & $842,77 *$ & $20,76^{*}$ & $9,70 *$ & $5,05^{\text {ns }}$ & $2,60^{\mathrm{ns}}$ & $60,91^{*}$ & $51,66^{*}$ & $62,03^{*}$ & $0,08^{\mathrm{ns}}$ & $12,78^{\mathrm{ns}}$ & $5,20^{\mathrm{ns}}$ & $158,39^{\text {ns }}$ \\
\hline CV $(\%)$ & 9,51 & 16,01 & 12,74 & 7,03 & 40,79 & 44,42 & 5,49 & 5,08 & 3,97 & 11,36 & 10,34 & 1,86 & 9,58 \\
\hline
\end{tabular}

RP: rendimento de polpa, em \%; PF: peso do fruto, em g; CF: comprimento do fruto, em cm; DF: diâmetro transversal, em cm; DCI: diâmetro da cavidade interna, em cm; FF: firmeza do fruto, em $\mathrm{kgf} \mathrm{cm}^{-2}$; AT: acidez titulável, em \% de ácido cítrico; SS: sólidos solúveis, em ${ }^{\circ}$ Brix; SS/AT: relação entre sólidos solúveis e acidez titulável; L* luminosidade; $\mathrm{C}^{*}$ (croma/saturação); h* (tonalidade/ângulo de cor). Médias $(\mathrm{n}=4)$ seguidas por letras iguais, na coluna, não diferem entre si, a 5 \%, pelo teste Tukey. ${ }^{\text {ns }}$ não significativo; $*$ significativo. 
garantindo-lhes maior longevidade em prateleiras. $\mathrm{O}$ amadurecimento do fruto é um processo natural, em que a firmeza da polpa diminui de 20 a 30 vezes (Jacomino et al. 2003). Segundo Fagundes \& Yamanishi (2001), a firmeza da polpa e do fruto são influenciadas por condições ambientais, cultivar, época de colheita e tratos culturais.

A aparência dos frutos envolve a combinação de seus atributos geométricos e cromáticos. Os atributos cromáticos estão associados à cor e são expressos pelos parâmetros $\mathrm{L}^{*}, \mathrm{C}^{*} \mathrm{e} \mathrm{h}^{*}$. Os dados de cor obtidos para os genótipos do grupo Solo indicaram que houve diferença significativa para os parâmetros $\mathrm{L}^{*}, \mathrm{C}^{*} \mathrm{e}$ $\mathrm{h}^{*}$ da polpa (Tabela 1).

A coordenada $L^{*}$ varia do preto puro (0) ao branco puro (100), portanto, a variedade L47-05 apresentou coloração mais escura da polpa $(64,57)$ e o híbrido H54.78 coloração mais clara $(52,48)$. Quanto ao croma $\left(\mathrm{C}^{*}\right)$, obteve-se valor superior para a polpa da linhagem L47-05 $(61,69)$, indicando coloração mais intensa desse genótipo, em relação aos demais. $\mathrm{O}$ ângulo de cor ( $\mathrm{h} *$ ) é amplamente usado como ferramenta analítica para avaliar se a cor é percebida como vermelha, amarela, verde ou azul. Assim, os valores de $h^{*}$ variam de 0 (vermelho puro), 90 (amarelo puro) e 180 (verde puro) a 270 (azul puro) (Ramallo \& Mascheroni 2012). Observou-se que, em média, todos os genótipos apresentam valores de $h^{*}$ inferiores a 90 (entre 53,70 e 67,06), confirmando que a cor da polpa desses genótipos está entre o vermelho e o amarelo, estando mais próxima do alaranjado. A linhagem L47-05 foi a que mais se aproximou da cor amarela, já que apresentou o maior valor de $\mathrm{h}^{*}$ $(67,06)$, e diferiu significativamente da L47-08, que se aproximou mais da cor vermelha $(53,70)$.

Verificou-se que a linhagem L47-08 apresentou elevada acidez titulável (AT) $(0,11 \%)$ e diferiu estatisticamente da linhagem L60, que apresentou baixo teor $(0,08 \%)$ (Tabela 1$)$. Valores mais elevados de acidez (acima de $0,11 \%$ de ácido cítrico) foram verificados por Santana et al. (2004), em genótipos do Banco Ativo de Germoplasma da Embrapa Mandioca e Fruticultura. Dias et al. (2011) relataram maior faixa de variação para a acidez titulável $(0,05-0,14 \%)$, em genótipos de mamoeiro, e Brito Neto et al. (2011) encontraram variações de $0,044 \%$ a $0,283 \%$ de ácido cítrico.

Os frutos dos genótipos do grupo Solo apresentaram variação no teor de sólidos solúveis de 11,15$15,10^{\circ}$ Brix. Três dos genótipos melhorados do grupo Solo avaliados (L47-05, L47-08 e H54.78) apresen- taram teor de sólidos solúveis acima de $14{ }^{\circ}$ Brix, não diferindo daquele apresentado pela testemunha Sunrise Solo (Tabela 1). O genótipo L60 apresentou o menor teor de sólidos solúveis $\left(11,15^{\circ} \mathrm{Brix}\right)$. Diferentes variações nos teores de sólidos solúveis, em frutos de mamoeiro, foram relatadas por Fagundes \& Yamanishi (2001) (9,9-12,5 ${ }^{\circ}$ Brix); Santana et al. (2004) (9-14 ${ }^{\circ}$ Brix); Ocampo et al. (2006) (4,6-13,3 ${ }^{\circ}$ Brix); Silva et al. (2008) $\left(10,24-12,27^{\circ}\right.$ Brix $)$; e Brito Neto et al. 2011 (7-14 ${ }^{\circ}$ Brix $)$.

Não houve diferença significativa $(\mathrm{p}>0,05)$ entre os valores de $\mathrm{pH}$ e razão SS/AT dos frutos dos genótipos do grupo Solo, com valores médios de 5,25 e 158,01, respectivamente (Tabela 1). Fagundes \& Yamanishi (2001) encontraram variações de SS/AT, em mamões do grupo Solo, com faixa mais ampla do que a obtida no presente estudo, que variou de 74,7 a 275,7, ao longo de 12 meses de comercialização. Já Oliveira et al. (2010) observaram amplitude de 25,90 a 360,79, ao avaliarem 19 acessos de mamoeiro. A relação SS/ AT representa o balanço entre os açúcares e os ácidos dos frutos e contribui diretamente para a formação de sabor e aroma. Geralmente, frutos com maiores valores de SS/AT apresentam doçura mais pronunciada e menor acidez, sendo preferidos pelos consumidores.

Considerando-se os genótipos do grupo Formosa, verificou-se que a testemunha Tainung $\mathrm{n}^{\mathrm{o}} 1$ apresentou os maiores valores para as variáveis $\mathrm{PF}$ $(1.146 \mathrm{~g}), \mathrm{CF}(25,73 \mathrm{~cm})$ e DF $(10,97 \mathrm{~cm})$, em relação aos genótipos melhorados (Tabela 1). Esses resultados revelam que os genótipos melhorados podem atender famílias menores ou consumidores individuais.

Reis et al. (2015) também obtiveram oito genótipos melhorados do grupo Formosa com peso de fruto inferior $(759,25-1.119,54 \mathrm{~g})$ ao da testemunha Tainung $\mathrm{n}^{\mathrm{o}} 1$ (1.146,27 g). Esses autores sugeriram que essa variação permite a seleção de plantas que produzam frutos com padrões que atendam diferentes nichos de mercado, seja de consumidores de frutos in natura ou agroindústrias. Souza et al. (2009) estudaram frutos do híbrido Tainung $\mathrm{n}^{\circ} 1$ e obtiveram média de diâmetro do fruto semelhante $(10,31 \mathrm{~cm})$ à do presente estudo e comprimento inferior $(20,53 \mathrm{~cm})$.

As medidas instrumentais de cor $\mathrm{L}^{*}, \mathrm{C}^{*} \mathrm{e}$ $\mathrm{h}^{*}$ diferiram estatisticamente, sendo que o híbrido H36.45 do grupo Formosa apresentou coloração mais clara $\left(\mathrm{L}^{*}=66,35\right)$ e intensa $\left(\mathrm{C}^{*}=58,92\right)$ do que os demais. Esse genótipo apresenta polpa com tonalidade mais próxima da cor amarela $\left(h^{*}=72,53\right)$. 
Não houve diferença significativa entre as demais características dos genótipos do grupo Formosa (Tabela 1), mostrando que os novos genótipos apresentaram características semelhantes à testemunha Tainung $\mathrm{n}^{\mathrm{o}} 1$.

Os resultados do teste de aceitação sensorial e as porcentagens de aprovação (escores de 6 a 9 ) dos frutos dos genótipos de mamoeiro dos grupos Solo e Formosa são apresentados na Tabela 2.

Observou-se que houve diferença significativa $(p<0,05)$ entre os genótipos do grupo Solo, para os seis atributos avaliados. O híbrido H54.78 foi estatisticamente igual à testemunha Sunrise Solo, para todos os atributos, e apresentou percentual de aprovação superior ao da testemunha Sunrise Solo para aparência interna $(96,15 \%)$, cor $(100 \%)$ e sabor $(98,08 \%)$, e inferior para o aroma $(78,85 \%)$, textura $(82,69 \%) \mathrm{e}$ aceitação global (94,23 \%). Esse resultado é importante, pois demonstra que se esse novo híbrido for disponibilizado para o mercado, terá aceitação tão elevada quanto à da testemunha Sunrise Solo. No geral, quatro dos cinco genótipos do grupo Solo avaliados (CMF L47-08, CMF L60, H54.78 e Sunrise Solo) apresentaram elevada aceitação, com notas superiores a 6,81 e percentuais de aprovação superiores a $78 \%$ (Tabela 2).

A linhagem L47-05 recebeu as menores notas médias para os atributos aparência interna $(5,5), \operatorname{cor}(5,5)$ e aroma $(6,5)$. Esse mesmo genótipo ainda teve a menor aprovação da aparência interna (67 \%) e da cor (63\%) e, consequentemente, menor aceitação global (78 \%)
(Tabela 2). É possível inferir que a menor aceitação dessa linhagem seja decorrente de sua coloração amarela (Tabela 1), o que demonstra que os consumidores preferem genótipos com coloração vermelha da polpa.

Os resultados obtidos por Santana et al. (2004) corroboram os do presente trabalho. Esses autores avaliaram sensorialmente frutos de genótipos de mamoeiro do grupo Solo e Formosa e obtiveram as menores notas para um genótipo de coloração amarela (CMF047), com média correspondente a "desgostei ligeiramente". Os autores afirmaram que a coloração amarela não é muito apreciada pelos consumidores de mamão, já que associaram as colorações vermelho-alaranjadas, presentes nos demais genótipos, aos frutos de melhor qualidade.

Não houve diferença significativa $(p>0,05)$ entre os genótipos do grupo Formosa, para todos os atributos sensoriais avaliados (Tabela 2), o que demonstra o potencial do híbrido H36.45 e da linhagem L33 para competirem com a variedade Formosa, que é bastante apreciada pelos consumidores. Esses genótipos tiveram índices de aprovação superiores ao da testemunha Tainung $\mathrm{n}^{\mathrm{o}} 1$, para aparência interna, cor, sabor e textura (Tabela 2).

Pelo diagnóstico de atributos realizado para os genótipos do grupo Solo (Tabela 3), constatou-se que os consumidores consideraram como mais escura a polpa dos frutos das linhagens L47-08, Sunrise Solo e do híbrido H54.78. Esses mesmos genótipos foram os mais apreciados, com relação à cor, pelos consumidores (Tabela 2). Não houve diferença significativa entre os genótipos, quanto à intensidade do aroma,

Tabela 2. Valores hedônicos médios de aceitação das amostras de genótipos de mamão do grupo Solo (Cruz das Almas, BA, 2015).

\begin{tabular}{|c|c|c|c|c|c|c|c|c|c|c|c|c|}
\hline \multirow{3}{*}{ Genótipo } & \multicolumn{12}{|c|}{ Grupo Solo } \\
\hline & \multicolumn{2}{|c|}{ Aparência interna } & \multicolumn{2}{|r|}{ Cor } & \multicolumn{2}{|c|}{ Aroma } & \multicolumn{2}{|c|}{ Sabor } & \multicolumn{2}{|c|}{ Textura } & \multicolumn{2}{|c|}{ Aceitação global } \\
\hline & Média $^{1}$ & Aprovação $^{2}$ & Média & Aprovação & Média & Aprovação & Média & Aprovação & Média & Aprovação & Média & Aprovação \\
\hline L47-05 & $5,50 \mathrm{c}$ & 67,30 & $5,50 \mathrm{c}$ & 63,50 & $6,50 \mathrm{c}$ & 80,70 & $6,70 \mathrm{~b}$ & 82,70 & $6,40 \mathrm{~b}$ & 76,90 & $6,40 \mathrm{~b}$ & 78,40 \\
\hline L47-08 & $7,30 \mathrm{ab}$ & 92,30 & $7,60 \mathrm{a}$ & 90,40 & $6,70 \mathrm{ab}$ & 80,70 & $6,80 \mathrm{~b}$ & 80,80 & $6,60 a b$ & 78,40 & $6,90 \mathrm{ab}$ & 86,30 \\
\hline L60 & $6,70 \mathrm{~b}$ & 88,50 & $6,70 \mathrm{~b}$ & 88,50 & $6,70 \mathrm{ab}$ & 84,60 & $6,90 \mathrm{~b}$ & 88,50 & $6,80 \mathrm{ab}$ & 82,70 & $6,90 \mathrm{ab}$ & 86,50 \\
\hline H54.78 & $7,70 \mathrm{a}$ & 96,20 & $7,80 \mathrm{a}$ & 100,00 & $6,80 \mathrm{ab}$ & 78,80 & $7,80 \mathrm{a}$ & 98,10 & $7,00 \mathrm{ab}$ & 82,70 & $7,40 \mathrm{a}$ & 94,20 \\
\hline Sunrise Solo & $7,40 \mathrm{ab}$ & 92,30 & $7,50 \mathrm{a}$ & 94,20 & $7,40 \mathrm{a}$ & 90,40 & $7,90 \mathrm{a}$ & 94,20 & $7,50 \mathrm{a}$ & 94,20 & $7,60 \mathrm{a}$ & 98,00 \\
\hline Média & $6,90^{*}$ & 87,30 & $7,00 *$ & 87,30 & $6,80^{*}$ & 83,10 & $7,20^{*}$ & 88,90 & $6,90 *$ & 83,00 & $7,10^{*}$ & 88,70 \\
\hline $\mathrm{CV}(\%)$ & 20,08 & - & 20,32 & - & 22,30 & - & 20,75 & - & 25,86 & - & 22,06 & - \\
\hline \multicolumn{13}{|c|}{ Grupo Formosa } \\
\hline \multirow{2}{*}{ Genótipo } & \multicolumn{2}{|c|}{ Aparência interna } & \multicolumn{2}{|r|}{ Cor } & \multicolumn{2}{|c|}{ Aroma } & \multicolumn{2}{|c|}{ Sabor } & \multicolumn{2}{|c|}{ Textura } & \multicolumn{2}{|c|}{ Aceitação global } \\
\hline & Média & Aprovação & Média & Aprovação & Média & Aprovação & Média & Aprovação & Média & Aprovação & Média & Aprovação \\
\hline H36.45 & $6,90 \mathrm{a}$ & 98,08 & $7,38 \mathrm{a}$ & 96,15 & $7,00 \mathrm{a}$ & 84,62 & $7,37 \mathrm{a}$ & 88,46 & $6,87 \mathrm{a}$ & 86,54 & $7,23 \mathrm{a}$ & 86,54 \\
\hline L33 & $6,90 \mathrm{a}$ & 86,54 & $7,31 \mathrm{a}$ & 94,23 & $7,19 \mathrm{a}$ & 94,23 & $7,42 \mathrm{a}$ & 94,23 & $6,69 \mathrm{a}$ & 88,46 & $7,21 \mathrm{a}$ & 92,31 \\
\hline Tainung $n^{\circ} 1$ & $7,30 \mathrm{a}$ & 96,08 & $7,06 \mathrm{a}$ & 92,31 & $6,63 \mathrm{a}$ & 86,54 & $6,69 \mathrm{a}$ & 82,69 & $7,10 \mathrm{a}$ & 82,69 & $6,83 \mathrm{a}$ & 92,31 \\
\hline Média & $7,00^{\mathrm{ns}}$ & 93,60 & $7,30^{\mathrm{ns}}$ & 94,20 & $6,90^{\mathrm{ns}}$ & 88,50 & $7,20 *$ & 88,50 & $6,90^{\text {ns }}$ & 85,90 & $7,09^{\mathrm{ns}}$ & 90,40 \\
\hline CV (\%) & 18,82 & - & 17,21 & - & 20,71 & - & 22,24 & - & 22,64 & - & 17,93 & - \\
\hline
\end{tabular}


Tabela 3. Valores médios do teste de diagnóstico de atributos, para a intensidade da cor, aroma, sabor e textura na boca, de frutos de genótipos de mamoeiro do grupo Solo e Formosa (Cruz das Almas, BA, 2015).

\begin{tabular}{lcccc}
\hline \multirow{2}{*}{ Genótipo } & \multicolumn{4}{c}{ Grupo Solo } \\
\cline { 2 - 5 } & Cor $^{1}$ & Aroma $^{2}$ & Sabor $^{3}$ & Textura $^{4}$ \\
\hline L47-05 & $3,40 \mathrm{c}$ & $5,60 \mathrm{a}$ & $5,90 \mathrm{~b}$ & $6,10 \mathrm{a}$ \\
L47-08 & $6,20 \mathrm{a}$ & $5,50 \mathrm{a}$ & $6,00 \mathrm{~b}$ & $5,90 \mathrm{a}$ \\
L60 & $4,90 \mathrm{~b}$ & $5,20 \mathrm{a}$ & $5,80 \mathrm{~b}$ & $4,80 \mathrm{~b}$ \\
H54.78 & $6,60 \mathrm{a}$ & $5,60 \mathrm{a}$ & $6,50 \mathrm{ab}$ & $5,00 \mathrm{~b}$ \\
Sunrise Solo & $6,90 \mathrm{a}$ & $5,80 \mathrm{a}$ & $7,10 \mathrm{a}$ & $5,70 \mathrm{ab}$ \\
\hline Média & $5,60^{*}$ & $5,50^{\text {ns }}$ & $6,30^{*}$ & $5,50^{*}$ \\
\hline CV (\%) & 28,68 & 38,02 & 29,55 \\
\hline \multirow{2}{*}{ Genótipo } & \multicolumn{4}{c}{ Grupo Formosa } \\
\cline { 2 - 5 } & Cor & Aroma & Sabor & Textura \\
\hline H36.45 & $6,30 \mathrm{a}$ & $5,50 \mathrm{ab}$ & $6,30 \mathrm{ab}$ & $4,40 \mathrm{~b}$ \\
L33 & $6,60 \mathrm{a}$ & $6,30 \mathrm{a}$ & $6,60 \mathrm{a}$ & $5,10 \mathrm{ab}$ \\
Tainung n ${ }^{\circ} 1$ & $5,30 \mathrm{~b}$ & $5,10 \mathrm{~b}$ & $5,60 \mathrm{~b}$ & $5,40 \mathrm{a}$ \\
\hline Média & $6,10^{*}$ & $5,70 *$ & $6,00^{*}$ & $5,00^{*}$ \\
\hline CV (\%) & 27,57 & 30,00 & 29,76 & 34,58 \\
\hline
\end{tabular}

${ }^{1}$ Muito clara (1) a muito escura (9); ${ }^{2}$ fraco (1) a forte $(9) ;{ }^{3}$ fraco (1) a forte (9); ${ }^{4}$ muito mole (1) a muito dura (9). $*$, ns significativo a $5 \%$ e não significativo, respectivamente, pelo teste $\mathrm{F}$. Médias $(\mathrm{n}=52)$ seguidas por letras iguais, na coluna, não diferem entre si a $5 \%$, pelo teste Tukey. e os valores obtidos foram intermediários $(5,52)$, ou seja, com aroma nem fraco e nem forte. A testemunha Sunrise Solo e o híbrido H54.78 apresentaram sabor mais forte (Tabela 3 ) e foram mais apreciados pelos consumidores (Tabela 2). Com relação à textura, os consumidores consideraram mais duros os frutos das variedades Sunrise Solo, L47-08 e L47-05.

O diagnóstico de atributos dos frutos dos genótipos do grupo Formosa (Tabela 3) mostrou que os frutos da linhagem L33 apresentaram atributos de cor, aroma e sabor em maior intensidade do que os frutos do híbrido Tainung $\mathrm{n}^{\mathrm{o}} 1$. Entretanto, tais características não influenciaram na aceitação sensorial, uma vez que não houve diferença significativa quanto à aceitação desses genótipos (Tabela 2).

Para a análise de intenção de compra realizada antes da degustação, ou seja, após a avaliação da aparência interna dos frutos, agruparam-se as categorias "certamente compraria" e "possivelmente compraria". Essa análise revelou, para o grupo Solo, maior intenção de compra para os frutos dos genótipos H54.78 (82,7 \%) e Sunrise Solo (80,8 \%) (Figura 1A). Após o consumo dos frutos, as intenções de compra desses genótipos aumentaram para $84,6 \%$
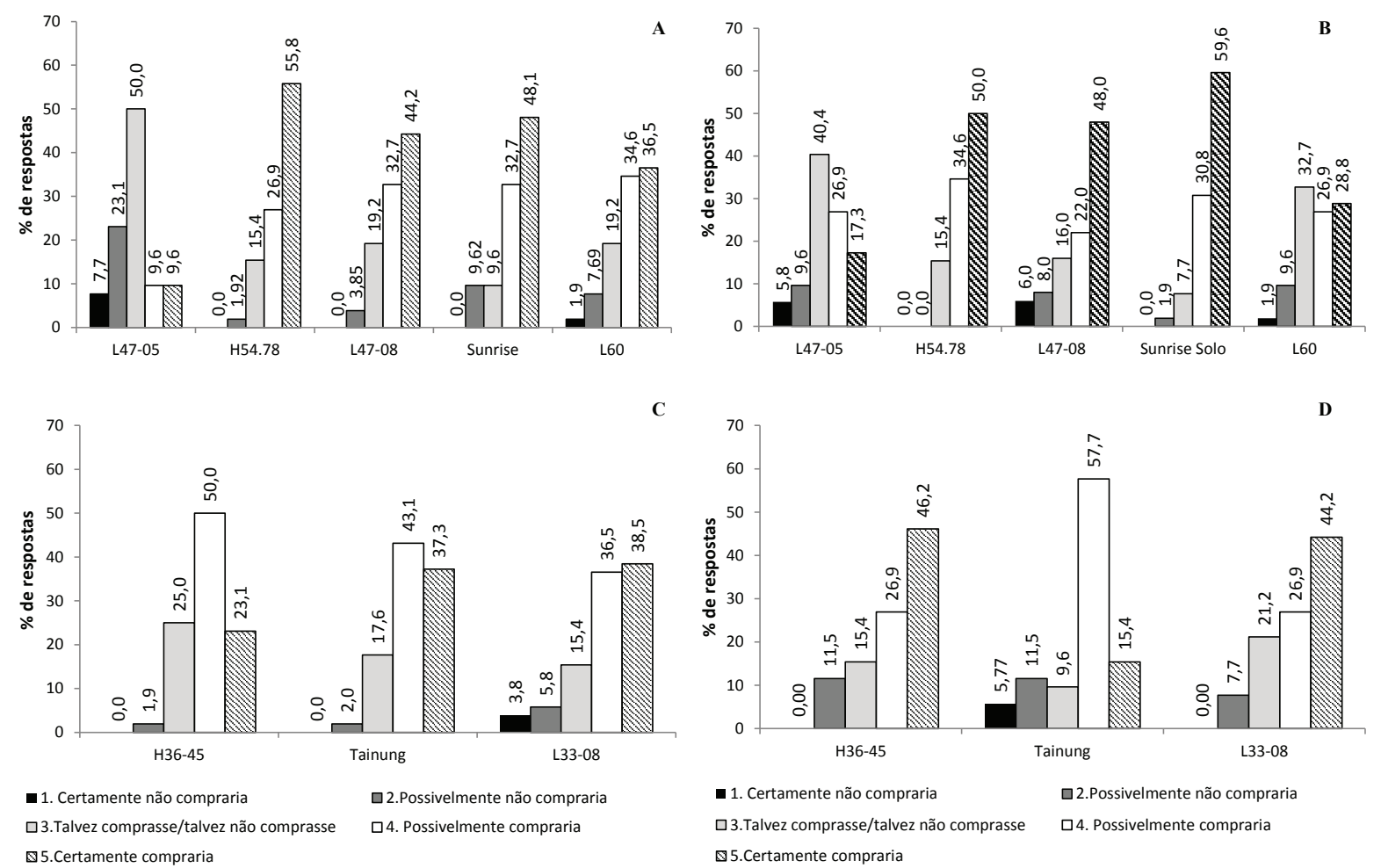

Figura 1. Intenção de compra de frutos de genótipos do grupo Solo (A e B) e Formosa (C e D) (Cruz das Almas, BA, 2015). A e $\mathrm{C}$ - intenção de compra após a avaliação da aparência interna dos frutos; B e D - intenção de compra após a degustação dos frutos. 
e 90,4\%, respectivamente (Figura 1B). Já para os frutos da linhagem L60, a intenção de compra reduziu de 71,2 \% (antes da degustação) para 55,8 \% (após a degustação). Os frutos da linhagem L47-05 apresentaram menor intenção de compra antes $(19,2 \%)$ e após $(44,2 \%)$ a degustação dos mesmos.

Para os frutos do grupo Formosa, agrupando-se as categorias "certamente compraria" e "possivelmente compraria" (Figura 1C), antes da degustação, as intenções de compra foram de 73,1\%, $75 \%$ e $80,4 \%$, respectivamente para os genótipos H36.45, $\mathrm{L} 33$ e Tainung $\mathrm{n}^{\circ} 1$. Após a degustação, as intenções de compra dos frutos dos três genótipos foram praticamente iguais $(73,1 \%, 73,1 \%$ e $71,1 \%$, respectivamente) (Figura 1D).

\section{CONCLUSÕES}

1. Os consumidores preferem frutos de variedades que apresentam coloração vermelha da polpa.

2. O híbrido H54.78 é promissor para o mercado do grupo Solo.

3. O híbrido H36.45 e a linhagem L33 são promissores para o mercado do grupo Formosa.

\section{AGRADECIMENTOS}

À Empresa Brasileira de Pesquisa Agropecuária (Embrapa), Conselho Nacional de Desenvolvimento Científico e Tecnológico (CNPq) e Fundação de Amparo à Pesquisa do Estado da Bahia (Fapesb), pelo apoio financeiro.

\section{REFERÊNCIAS}

BRITO NETO, J. F. et al. Produtividade e qualidade de frutos de mamoeiro Sunrise Solo em função de doses de nitrogênio e boro. Semina: Ciências Agrárias, Londrina, v. 32, n. 1, p. 69-80, 2011.

DIAS, N. L. P.; OLIVEIRA, E. J.; DANTAS, J. L. L. Avaliação de genótipos de mamoeiro com uso de descritores agronômicos e estimação de parâmetros genéticos. Pesquisa Agropecuária Brasileira, Brasília, DF, v. 46, n. 11, p. 1471-1479, 2011.

FAGUNDES, G. R.; YAMANISHI, O. K. Características físicas e químicas de frutos de mamoeiro do grupo Solo comercializados em 4 estabelecimentos de Brasília - DF. Revista Brasileira de Fruticultura, Jaboticabal, v. 23, n. 3, p. 541-545, 2001.

FERREIRA, D. F. Sisvar: sistema de análise de variância. Versão 5.3. Lavras: UFLa, 2010.
FOOD AND AGRICULTURE ORGANIZATION OF THE UNITED NATIONS (FAO). FAO statistics agriculture database. 2013. Disponível em: <http://www. fao.org>. Acesso em: 11 mar. 2014.

INSTITUTO ADOLFO LUTZ (IAL). Métodos físicoquímicos para análise de alimentos. 4. ed. Brasília, DF: Ministério da Saúde, 2008.

INSTITUTO BRASILEIRO DE GEOGRAFIA E ESTATÍSTICA (IBGE). Levantamento sistemático da produção agrícola. 2013. Disponível em: <ftp://ftp.ibge. gov.br/Producao_Agricola/Levantamento_Sistematico_ da_Producao_Agricola_[mensal]/Fasciculo/lspa_201401. pdf $>$. Acesso em: 20 mar. 2014.

JACOMINO, A. P.; BRON, L. U.; KLUGE, R. A. Avanços em tecnologia pós-colheita de mamão. In: MARTINS, D. S. (Ed.). Papaya Brasil: qualidade do mamão para o mercado interno. Vitória: Incaper, 2003. p. 283-293.

MARTINS, D. S.; COSTA, A. F. S. A cultura do mamoeiro: tecnologias de produção. Vitória: Incaper, 2003.

MEILGAARD, M.; CIVILLE, G. V.; CARR, B. T. Sensory evaluation techniques. 4. ed. Boca Raton: CRC Press, 2006.

OCAMPO, J. et al. Organization of morphological and genetic diversity of Caribbean and Venezuelan papaya germplasm. Fruits, Montpellier, v. 61, n. 1, p. 25-37, 2006.

OLIVEIRA, E. J. et al. Correlações genéticas e análise de trilha para número de frutos comerciais por plantas em mamoeiro. Pesquisa Agropecuária Brasileira, Brasília, DF, v. 45, n. 8, p. 855-862, 2010.

RAMALLO, L. A.; MASCHERONI, R. H. Quality evaluation of pineapple fruit during drying process. Food and Bioproducts Processing, London, v. 90, n. 2, p. 275283, 2012.

REIS, R. C. et al. Caracterização físico-química de frutos de novos híbridos e linhagens de mamoeiro. Pesquisa Agropecuária Brasileira, Brasília, DF, v. 50, n. 3, p. 210217, 2015.

SANTANA, L. R. R.; MATSUURA, F. C. A. U.; CARDOSO, R. L. Genótipos melhorados de mamão (Carica papaya L.): avaliação sensorial e físico-química dos frutos. Ciência e Tecnologia de Alimentos, Campinas, v. 24, n. 2, p. 217-222, 2004.

SILVA, F. F. et al. Estimation of genetic parameters related to morpho-agronomic and fruit quality traits of papaya. Crop Breeding and Applied Biotechnology, Viçosa, v. 8, n. 1, p. 65-73, 2008.

SOUZA, T. V. et al. Avaliação física e química de frutos de mamoeiro Tainung $\mathrm{n}^{\circ} 1$, fertirrigado com diferentes combinações de fontes nitrogenadas. Revista Brasileira de Ciências Agrárias, Recife, v. 4, n. 2, p. 179-184, 2009.

TABELA BRASILEIRA DE COMPOSIÇÃO DE ALIMENTOS (Taco). 4. ed. Campinas: NEPA-Unicamp, 2011. 